University of Wollongong

Research Online

Faculty of Engineering and Information

Faculty of Engineering and Information

Sciences - Papers: Part A

Sciences

$1-1-2015$

Development of a predictive framework to assess the removal of trace organic chemicals by anaerobic membrane bioreactor

\author{
Kaushalya C. Wijekoon \\ University of Wollongong, kcw998@uowmail.edu.au \\ James McDonald \\ University of New South Wales \\ Stuart J. Khan \\ University of New South Wales, s.khan@unsw.edu.au \\ Faisal I. Hai \\ University of Wollongong, faisal@uow.edu.au \\ William E. Price \\ University of Wollongong, wprice@uow.edu.au
}

See next page for additional authors

Follow this and additional works at: https://ro.uow.edu.au/eispapers

Part of the Engineering Commons, and the Science and Technology Studies Commons

Research Online is the open access institutional repository for the University of Wollongong. For further information contact the UOW Library: research-pubs@uow.edu.au 


\title{
Development of a predictive framework to assess the removal of trace organic chemicals by anaerobic membrane bioreactor
}

\author{
Abstract \\ This study aims to develop a predictive framework to assess the removal and fate of trace organic \\ chemicals (TrOCs) during wastewater treatment by anaerobic membrane bioreactor (AnMBR). The fate of \\ 27 TrOCs in both the liquid and sludge phases during AnMBR treatment was systematically investigated. \\ The results demonstrate a relationship between hydrophobicity and specific molecular features of TrOCs \\ and their removal efficiency. These molecular features include the presence of electron withdrawing \\ groups (EWGs) or donating groups (EDGs), especially those containing nitrogen and sulphur. All seven \\ hydrophobic contaminants were well removed $(>70 \%)$ by AnMBR treatment. Most hydrophilic TrOCs \\ containing EDGs were also well removed (>70\%). In contrast, hydrophilic TrOCs containing EWGs were \\ mostly poorly removed and could accumulate in the sludge phase. The removal of several nitrogen/ \\ sulphur bearing TrOCs (e.g., linuron and caffeine) by AnMBR was higher than that by aerobic treatment, \\ possibly due to nitrogen or sulphur reducing bacteria.

\section{Disciplines} \\ Engineering | Science and Technology Studies

\section{Publication Details} \\ Wijekoon, K. C., McDonald, J. A., Khan, S. J., Hai, F. I.., Price, W. E. \& Nghiem, L. D. (2015). Development of \\ a predictive framework to assess the removal of trace organic chemicals by anaerobic membrane \\ bioreactor. Bioresource Technology, 189 391-398.
}

\section{Authors}

Kaushalya C. Wijekoon, James McDonald, Stuart J. Khan, Faisal I. Hai, William E. Price, and Long D. Nghiem 


\title{
Development of a predictive framework to assess the removal of trace organic chemicals by anaerobic membrane bioreactor
}

\author{
Revised Manuscript Submitted to
}

\section{Bioresource Technology}

April 2015

Kaushalya C. Wijekoon ${ }^{\text {a }}$, James McDonald ${ }^{\mathrm{b}}$, Stuart J. Khan ${ }^{\mathrm{b}}$, Faisal I. Hai ${ }^{\mathrm{a}}$, William E. Price ${ }^{c}$ and Long D. Nghiem ${ }^{a} *$

${ }^{a}$ Strategic Water Infrastructure Laboratory, School of Civil Mining and Environmental Engineering, University of Wollongong, Wollongong, NSW 2522, Australia

${ }^{\mathrm{b}}$ School of Civil \& Environmental Engineering, University of New South Wales, NSW 2052, Australia

${ }^{c}$ Strategic Water Infrastructure Laboratory, School of Chemistry

University of Wollongong, Wollongong, NSW 2522, Australia

* Corresponding author: Long Duc Nghiem; Email: longn@uow.edu.au; Ph +61 242214590 


\section{Abstract}

This study aims to develop a predictive framework to assess the removal and fate of trace organic chemicals (TrOCs) during wastewater treatment by anaerobic membrane bioreactor (AnMBR). The fate of 27 TrOCs in both the liquid and sludge phases during AnMBR treatment was systematically investigated. The results demonstrate a relationship between hydrophobicity and specific molecular features of TrOCs and their removal efficiency. These molecular features include the presence of molecular electron withdrawing groups (EWGs) or donating groups (EDGs), nitrogen and sulphur. All seven hydrophobic contaminants were well removed (>70\%) by AnMBR treatment. Most hydrophilic TrOCs containing EDGs were also well removed $(>70 \%)$. In contrast, hydrophilic TrOCs containing EWGs were mostly poorly removed and could accumulate in the sludge phase. The removal of several nitrogen/sulphur bearing TrOCs (e.g., linuron and caffeine) by AnMBR was higher than that by aerobic treatment, possibly due to nitrogen or sulphur reducing bacteria.

Keywords: Anaerobic membrane bioreactor (AnMBR); trace organic chemicals (TrOCs); hydrophobicity; functional groups; biodegradation/transformation.

\section{Introduction}

Aerobic and anaerobic processes are widely used for wastewater treatment. Both processes can be integrated with membrane filtration to form an aerobic or anaerobic membrane bioreactor (MBR). MBR processes have attracted significant scientific and industry attention over the last few decades. In particular, given their ability to treat concentrated wastewater and simultaneously produce biogas, which is an important renewable fuel, the number of scientific studies, as well as practical application of anaerobic membrane bioreactors (AnMBRs), have increased significantly (Liao et al., 2006; Shoener et al., 2014; Visvanathan and Abeynayaka, 2012).

Of significant interest during wastewater treatment is the removal of trace organic chemicals (TrOCs) for environmental protection as well as water reuse application requirements. A large number of TrOCs have been detected in raw sewage and sewage-impacted water bodies around the world. These include steroid hormones, pharmaceuticals, personal care products, surfactants, 
pesticides, and disinfection by-products (Alidina et al., 2014; Brack et al., 2015; Luo et al., 2014; Osorio et al., 2012; Tran et al., 2014; Tran et al., 2013). Their occurrence in the aquatic environment is of concern to public health and the environment because many of them are known or suspected to have an adverse impact on living organisms including human beings (Schwarzenbach et al., 2006).

The removal of TrOCs by MBR has been intensively studied for the last twenty years. However, previous studies have focussed almost exclusively on the aerobic MBR process rather than its AnMBR counterpart. Indeed, previous studies have allowed us to develop a comprehensive understanding of the fate and removal of TrOCs during aerobic MBR treatment. By contrast, there is a dearth of information regarding the removal of TrOCs by AnMBR. Monsalvo et al. (2014) appears to be the only study that has addressed the removal of TrOCs by AnMBR.

Numerous studies have investigated the removal and removal mechanisms of TrOCs by aerobic MBR treatment (Clara et al., 2005b; Navaratna et al., 2012; Tadkaew et al., 2011; Wijekoon et al., 2013). It is well established that both biodegradation and adsorption can govern the removal of TrOCs from the aqueous phase during aerobic MBR treatment. In addition, molecular structure is an important factor for aerobic biodegradation of TrOCs. Tadkaew et al. (2011) developed a qualitative framework for assessing the removal of TrOCs by aerobic MBR treatment based on their hydrophobicity and the presence of molecular electron donating groups (EDGs) or electron withdrawing groups (EWGs). Data reported by Tadkaew et al. (2011) demonstrated that TrOCs with EDGs (e.g. hydroxyl and amine) are effectively removed whereas TrOCs with EWGs (e.g. chloro and amide) in their structure are poorly removed by an aerobic MBR. In a subsequent study, Wijekoon et al. (2013) successfully extended this framework to elucidate the fate of TrOCs in the aqueous and sludge phases during aerobic MBR treatment. According to Wijekoon et al. (2013), recalcitrant and hydrophobic/hydrophilic contaminants are mainly removed via adsorption to sludge while readily biodegradable and hydrophobic/hydrophilic TrOC are mainly removed via biodegradation/transformation. Previous work also suggests that low dissolved oxygen conditions could favour the removal of some TrOCs (e.g., carbamazepine (Hai et al., 2011)) that are otherwise persistent to aerobic treatment. Similarly, there is evidence that nitrifying bacteria may also enhance the removal of some TrOCs (Vader et al., 2000; Wijekoon et al., 2013). 
Current knowledge on TrOC removal by AnMBR is still limited (Abargues et al., 2012; Monsalvo et al., 2014). Abargues et al. (2012) and Czajka and Londry (2006) reported that anaerobic removal of octylphenols, nonylphenols and $17 \alpha-$ ethinylestradiol is negligible. On the other hand, Monsalvo et al. (2014) reported considerably higher removal (20\%) of 17aethinylestradiol. This discrepancy in the current literature can be attributed to the fact that anaerobic biodegradation of TrOCs can take place in diverse microbial cultures. Anaerobic biodegradation of TrOCs can be carried out not only by the methanogenic archaea, but also sulphate reducing, iron reducing and nitrate reducing bacteria that act as the final electron acceptors (Czajka and Londry, 2006; Dionisi et al., 2006; Zeng et al., 2009). For example, in the

presence of nitrate, $17 \alpha$-ethinylestradiol can be effectively removed by biodegradation while in the absence of nitrate, removal of $17 \alpha$-ethinylestradiol adsorption to biosolids was the main removal mechanism (Zeng et al., 2009). In contrast, Czajka and Londry (2006), reported no biodegradation of $17 \alpha$-ethinylestradiol over 3 years of incubation period in isolated methanogenic, sulphate reducing, nitrate reducing or ion reducing conditions. Halogenated TrOCs (e.g., polyaromatic hydrocarbons) could be effectively biodegraded under anaerobic condition (Dionisi et al., 2006). Anaerobic reductive dehalogenation seems to be the main biodegradation mechanism for halogenated compounds - these compounds can be used as final electron acceptors by a number of anaerobic microorganisms (Dionisi et al., 2006).

This study aims to provide insight into the removal and fate of TrOCs during AnMBR treatment. The removal of several groups of TrOCs from both the aqueous and sludge phases was determined and related to the compound hydrophobicity and molecular characteristics in order to elucidate their removal mechanisms. A generalized framework for predicting the removal of TrOCs by AnMBR treatment was proposed based on the obtained results.

\section{Materials and methods}

\subsection{AnMBR experimental setup}

An AnMBR system was used consisting of a conical shaped $30 \mathrm{~L}$ stainless steel reactor and an external ceramic membrane module (NGK, Japan) as shown in Supplementary Data Figure S1. Hot water was circulated through a plastic tube wrapped around the reactor. The temperature of the circulated hot water was regulated by a PID controlled heater (Neslab RTE7, Thermo 
Scientific, USA). Mixed liquor was circulated at $42 \mathrm{~L} / \mathrm{hr}$ using a peristaltic pump (DULCOFlex, Prominent, Australia) to ensure complete mixing. A conductive level controller (Omron, Japan) connected to the feed pump was used to maintain the reactor working volume at $20 \mathrm{~L}$. The membrane module had a nominal pore size and effective surface area of $1 \mu \mathrm{m}$ and $0.09 \mathrm{~m}^{2}$, respectively. Peristaltic pumps (Masterflex L/S, USA) were used for feeding, recirculation and permeate extraction. Effluent from the AnMBR was circulated to the ceramic membrane on a cycle of $14 \mathrm{~min}$ on and $1 \mathrm{~min}$ off. The reactor and all pipework used in the AnMBR system were covered with insulation foam to minimize heat loss. Biogas production rate was monitored using a custom made gas counter. Biogas was collected via a Tedlar sampling bag prior to gas composition analysis.

\subsection{Experimental protocol}

The AnMBR was inoculated with anaerobic sludge from the Wollongong Wastewater Treatment Plant (Wollongong, Australia). A synthetic wastewater was used to simulate high strength domestic wastewater and to maintain stable operating conditions. The synthetic wastewater was prepared daily by diluting a concentrated stock solution with Milli-Q water to obtain $4000 \mathrm{mg} / \mathrm{L}$ glucose, $750 \mathrm{mg} / \mathrm{L}$ peptone, $175 \mathrm{mg} / \mathrm{L} \mathrm{KH}_{2} \mathrm{PO}_{4}, 175 \mathrm{mg} / \mathrm{L} \mathrm{MgCl}$, $2250 \mathrm{mg} / \mathrm{L} \mathrm{CH}_{3} \mathrm{COONa}$ and $175 \mathrm{mg} / \mathrm{L}$ urea (Alturki et al., 2012). Micronutrients, namely, $\mathrm{FeCl}_{2}(45 \mathrm{mg} / \mathrm{L}), \mathrm{NiCl}_{2}(10 \mathrm{mg} / \mathrm{L})$, $\mathrm{CoCl}_{2}(6 \mathrm{mg} / \mathrm{L})$, and $\left(\mathrm{NH}_{4}\right)_{6} \mathrm{Mo}_{7} \mathrm{O}_{24}(4 \mathrm{mg} / \mathrm{L})$ were added (Khanal, 2008). The concentrated stock solutions were prepared every week and kept at $4{ }^{\circ} \mathrm{C}$. Sodium bicarbonate was used to maintain the reactor $\mathrm{pH}$ at 7. Prior to the addition of the TrOCs to the influent, the MBR system was operated for approximately 4 months for acclimatisation.

Mixed liquor characteristics including suspended solids (MLSS), volatile suspended solids (MLVSS), pH, conductivity, oxidation reduction potential (ORP), alkalinity; organic removal efficiency in terms of chemical oxygen demand (COD) and total nitrogen (TN); and biogas production were monitored approximately twice a week. The digester temperature was set at 35 $\pm 1^{\circ} \mathrm{C}$. Hydraulic retention time, permeate flux and organic loading rate of bioreactor were 4 days, $1.8 \mathrm{~L} / \mathrm{m}^{2}$.h and $1.3 \mathrm{gCOD} / \mathrm{L} . \mathrm{d}$, respectively. Excess sludge was withdrawn every 3-4 days to maintain the MLSS concentration in the reactor at $10 \mathrm{~g} / \mathrm{L}$, resulting in a sludge retention time (SRT) of approximately 180 days. 
The mixed liquor was collected weekly and then centrifuged at $3270 \mathrm{xg}$ for $10 \mathrm{~min}$ (Alleegra X12R, Beckman Coulter, USA) to obtain sludge pellets for analysis of TrOCs in sludge. Feed and permeate samples were also collected for TrOC analysis on a weekly basis. The mass balance of each compound was conducted based on the compound concentration in the feed, permeate, and sludge.

TrOC removal by AnMBR is defined as:

$$
R=100 \times\left(1-\frac{C_{p}}{C_{F}}\right)
$$

where $C_{F}$ and $C_{p}$, are concentrations of the specific compound in the bioreactor feed and permeate, respectively. Biodegradation/transformation of TrOCs during AnMBR treatment was calculated by considering the mass balance of each compound in the feed, sludge and permeate as given in Equation 2.

$$
\mathrm{C}_{\mathrm{F}} \times \mathrm{V}_{\mathrm{F}}=\left(\mathrm{C}_{\mathrm{S} 1} \times X_{S l} \times \mathrm{V}_{\mathrm{S}}\right)+\left(C_{p} \times V_{p}\right)+\text { biodegradation/transformation }
$$

In Equation 2, $\mathrm{C}_{\mathrm{Sl}}$ is the compound concentration in sludge and $\mathrm{X}_{\mathrm{Sl}}$ denotes the sludge (MLSS) concentration. Similarly $V_{F}, V_{P}$, and $V_{S}$ are the volumes of the bioreactor feed, permeate, and mixed liquor, respectively.

\subsection{Target compounds}

A set of 27 TrOCs was selected for this investigation. The physicochemical properties of the selected compounds are listed in Supplementary Data Table S1. These compounds were selected based on their wide spread occurrence in domestic sewage and range of hydrophobicity and diverse molecular structure. The TrOCs selected also represented several key TrOC groups including pharmaceuticals, personal care products, industrial chemicals, and pesticides. A combined stock solution of all compounds was prepared in pure methanol and kept on $-18{ }^{\circ} \mathrm{C}$ in the dark. TrOCs were continually introduced into the synthetic wastewater at a concentration of approximately $5 \mu \mathrm{g} / \mathrm{L}$ of each compound as a representative of their environmental concentrations. The TrOC concentration was significantly lower than all other constituents in the feed (including micronutrients). However, it is noteworthy that the possibility of competitive or synergistic biodegradation of these compounds cannot be completely discounted. TrOC 
concentration of stock solution was analytically confirmed before introducing to the AnMBR system to ensure feed composition consistency.

\subsection{Analytical methods}

\subsubsection{Basic water quality parameters}

Biogas composition was measured using a biogas meter (Biogas 5000, Geotech, UK). The details of this measurement are available elsewhere (Nghiem et al., 2014). Alkalinity, MLSS and MLVSS were measured according to the Standard Methods for Examination of Water and Wastewater (Eaton and Franson, 2005). COD was measured according to a standard, dichromate method (Eaton and Franson, 2005) - high range plus digestion vials (Hatch, USA) were used for analysis. TN was analysed using a TN-V $\mathrm{V}_{\mathrm{CSH}}$ analyser (Shimadzu, Japan). Electrical conductivity and $\mathrm{pH}$ of the mixed liquor was monitored using an Orion 4 Star Plus portable $\mathrm{pH} /$ conductivity meter (Thermo Scientific, USA). ORP was measured using WP-80D dual pH-mV meter (TPS, Australia).

\subsubsection{TrOC analysis}

TrOC concentrations in the aqueous phase were determined by an analytical method consisting of solid phase extraction followed by liquid chromatography and quantitative determination by mass spectrometry previously reported by Tadkaew et al. (2011). Samples were spiked with a surrogate solution containing $50 \mathrm{ng}$ of an isotopically labeled version of each analyte.

Hydrophilic/lipophilic balance cartridges (Waters, Millford, MA, USA) were pre-conditioned with $5 \mathrm{~mL}$ of MTBE, $5 \mathrm{~mL}$ of methanol and reagent water $(2 \times 5 \mathrm{~mL})$ and were used for sample extraction. After solid phase extraction, the cartridges were rinsed with $(2 \times 5 \mathrm{~mL})$ of reagent water and dried with a stream of nitrogen for $30 \mathrm{~min}$. Loaded cartridges were stored at $4{ }^{\circ} \mathrm{C}$ in sealed bags until elution and analysis. Analytes were eluted from the cartridges with $5 \mathrm{~mL}$ of methanol followed by $5 \mathrm{~mL}$ of $1 / 9(\mathrm{v} / \mathrm{v})$ methanol/MTBE into centrifuge tubes. The resultant extract was concentrated under a stream of nitrogen to approximately $100 \mu \mathrm{L}$ and then diluted to a final volume of $1 \mathrm{~mL}$ with methanol.

Analytes were separated using an Agilent (Palo Alto, CA, USA) 1200 series high performance liquid chromatography (HPLC) system on a Luna C18 (2) column (Phenomenex, Torrence CA, USA). Peaks were identified and quantified by mass spectrometry using an API 4000 triple 
quadrupole mass spectrometer (Applied Biosystems, Foster City, CA, USA) equipped with a turbo-V ion source employed in both positive and negative electro-spray modes. The detection limit of this analytical method was $5 \mathrm{ng} / \mathrm{L}$ for all analytes except caffeine, triclocarban and diuron (10 ng/L) and bisphenol A (20 ng/L). Detailed description of the HPLC-MS/MS settings is available elsewhere (Tadkaew et al., 2011).

TrOC concentration in the solid phase (sludge) was determined according to a method previously described by Wijekoon et al. (2013). The solid pellets obtained from the mixed liquor after centrifugation were freeze-dried for $4 \mathrm{~h}$ using an Alpha 1-2 LDplus Freeze Dryer (Christ GmbH, Germany). The dried sludge was ground to powder and $0.75 \mathrm{~g}$ powder was transferred to a glass test tube for extraction. Methanol $(7.5 \mathrm{~mL})$ was added to the test tube, thoroughly mixed using a vortex mixer (VM1, Ratek, Australia) for $3 \mathrm{~min}$, and ultrasonicated for $10 \mathrm{~min}$ at $40{ }^{\circ} \mathrm{C}$. The sample was centrifuged at $3270 \mathrm{xg}$ for $10 \mathrm{~min}$ (Alleegra X-12R, Beckman Coulter, USA) and the supernatant was collected in a glass beaker for further analysis. A dichloromethane and methanol mixture (1:1 v:v) $(7.5 \mathrm{~mL})$ were added to the remaining sludge, and the process of mixing, ultrasonic extraction, and centrifugation was repeated. The supernatants from both steps were combined, and residual methanol and dichloromethane were purged using nitrogen gas. Finally, Milli-Q water was added to obtain a $500 \mathrm{~mL}$ aqueous sample. This sample was then analysed using the analytical method used for aqueous sample described above.

\section{Results and discussion}

\subsection{Biological performance}

Performance of the AnMBR system in terms of COD removal and biogas production was stable during the acclimatisation and TrOC experiment periods (Figure 1). COD removal was stable at around $84 \%$ while, as expected, $\mathrm{TN}$ removal was negligible and was mostly less than $20 \%$. The COD and TN removal efficiencies reported here are consistent with values in the literature (Ozgun et al., 2013). A small variation in COD removal was observed immediately after the introduction of TrOCs to the feed. However, it was fully recovered to around the average value of $84 \%$ after two weeks. The observed decrease in COD removal can be attributed to the addition of methanol, which is the solvent used to introduce the TrOCs to the influent. A small reduction 
in biogas production was also observed immediately after TrOC introduction, again, possibly due to methanol loading.

\section{[FIGURE 1]}

A stable performance of the AnMBR was also found with respect to biogas production. Methane yield of the AnMBR was $0.2 \mathrm{~L} \mathrm{CH}_{4} / \mathrm{g} \mathrm{COD}$, which is comparable with values previously reported in the literature (Chang and Hufnagel, 2013). The methane composition in biogas was also stable at around $61 \%$ which is in good agreement with typical anaerobic reactors (Khanal, 2008). Biogas production gradually increased during acclimatisation and stabilised at $5.4 \mathrm{~L} / \mathrm{d}$. Immediately after spiking TrOCs the biogas production slightly dropped to $4.8 \mathrm{~L} / \mathrm{d}$ due to methanol shock loading as mentioned before, then gradually recovered to at the average value of $5.4 \mathrm{~L} / \mathrm{d}$ in about two weeks. It is noteworthy that no discernible variation in biogas composition was observed after introducing TrOC to the feed. Conductivity, ORP and alkalinity of mixed liquor during the entire experiment were stable at around $3.8 \mathrm{mS} / \mathrm{cm}$ and $-200 \mathrm{mV}, 3100 \mathrm{mg}$ $\mathrm{CaCO}_{3} / \mathrm{L}$, respectively (Supplementary Data Figure S2). MLSS, MLVSS and MLVSS/MLSS ratio of the AnMBR during the experiment were also stable (Supplementary Data Figure S3). Results reported here show that the introduction of TrOCs to the feed did not affect basic performance of the AnMBR.

\subsection{TrOC removal}

As noted in the introduction, there is a dearth of information regarding the removal of TrOCs by AnMBR treatment. Thus, in addition to the only available study by Monsalvo et al. (2014), TrOC removal efficiencies from several other studies involving the use of conventional anaerobic treatment system were tabulated in Table 1 and compared to values obtained from our study. In most cases, the removal efficiencies obtained from our study are higher than those reported by Monsalvo et al. (2014) and other studies where a conventional anaerobic treatment system (i.e., without membrane separation) was used. The better TrOC performance observed here can be explained by the difference in operating conditions between our study and those in the literature. Monsalvo et al. (2014) operated their AnMBR at $30^{\circ} \mathrm{C}$ which was well below the typical temperature of an engineered anaerobic treatment system. In addition, the HRT of their AnMBR was only $6 \mathrm{~h}$ and was outside the typical anaerobic HRT range of $1-25 \mathrm{~d}$ (Chang, 
2014). It is also noteworthy that Monsalvo et al. (2014) did not report any biogas production data. Thus, it is plausible that their AnMBR system was operated under sub-optimal conditions.

\section{[TABLE 1]}

The average removal efficiency of each TrOC over the five weeks of experiment is summarised in the increasing order of their hydrophobicity (denoted by $\log D$ ) in Figure 2. Hydrophobicity appears to be a key property that governs the removal of TrOCs from the aqueous phase. Indeed, the removal efficiencies of all seven compounds with $\log D_{\mathrm{pH}} 7$ of 3.2 or higher were consistently higher than $70 \%$. Given their hydrophobicity, these compounds can readily adsorb to the sludge (solid) phase. In contrast, the removal efficiencies of hydrophilic TrOCs (i.e., Log $D_{\mathrm{pH}} 7^{<3.2)}$ varied significantly from almost no removal (e.g., diclofenac) to near complete removal (e.g., omeprazole). The biodegradability of an organic compound can be governed by their molecular structure and functional groups (Tadkaew et al., 2011). Thus, given the diverse molecular structure and specific functional groups of the hydrophilic TrOCs investigated here, the observed variation in their removal by AnMBR is not surprising.

\section{[FIGURE 2]}

Tadkaew et al. (2011) recently proposed a qualitative framework to predict TrOC removal based on the presence of EDG and EWG in their structures. During anaerobic respiration, certain inorganic chemicals such as $\mathrm{NO}_{3}{ }^{-}, \mathrm{SO}_{4}{ }^{2-}$, metals including iron $\left(\mathrm{Fe}^{3+}\right)$ and manganese $\left(\mathrm{Mn}^{4+}\right)$, or even $\mathrm{CO}_{2}$ can play the role that oxygen plays in case of aerobic degradation i.e., accepting electrons from the degraded contaminant. Given this similarity, it is likely that the framework proposed by Tadkaew et al. (2011) for aerobic MBR is also applicable in case of anaerobic MBRs. To verify this, the 27 TrOCs investigated in this study were divided into three groups (Figure 3). Group A contains hydrophilic compounds $\left(\log D_{\mathrm{pH}} 7<3.2\right)$ with at least one electron donating but no electron withdrawing functional group; group B contains hydrophilic compounds ( $\log D_{\mathrm{pH} 7}<3.2$ ) with at least one EWG functional group; and group $\mathrm{C}$ contains hydrophobic compounds ( $\left.\log D_{\mathrm{pH}} \geq 3.2\right)$. As can be seen from Figure 3, the presence of an electron donating functional group can render the compound amenable to anaerobic biodegradation. Indeed, with gemfibrozil being the only exception, all TrOCs in group A (hydrophilic with at least one EDG but no EWG) show more than 70\% removal efficiency. On the other hand, TrOCs with one or several electron withdrawing functional groups are persistent 
to anaerobic biodegradation (regardless whether they also contain electron donating functional groups). The removal efficiency of these TrOCs by AnMBR was below 50\% and several compounds (e.g., diclofenac and primidone) showed negligible removal.

\section{[FIGURE 3]}

Although the qualitative framework to predict TrOC removal can be adapted to anaerobic treatment, there are several significant differences in the removal of these TrOCs by AnMBR and aerobic MBR. The removal efficiencies of hydrophilic TrOCs containing sulphur or nitrogen in their molecular structure by AnMBR reported here are higher than those by aerobic MBR previously reported in the literature, except for atenolol, paracetamol and diclofenac (Table 2). Notable examples include sulfamethoxazole, carbamazepine, linuron, omeprazole, and atrazine. The higher removal of carbamazepine by anaerobic treatment reported here is consistent with a previous study by Hai et al. (2011) who also showed significantly higher carbamazepine removal under near anoxic compared to aerobic conditions. On the other hand, the removal efficiencies of hydrophilic contaminants not containing sulphur or nitrogen in their molecular structure (e.g., ketoprofen, ibuprofen and gemfibrozil) are significantly lower than their removal by aerobic MBR (Table 2). The removal efficiencies of sulphur or nitrogen bearing and hydrophobic TrOCs by AnMBR are also higher than that by aerobic MBR previously reported by Tadkaew et al. (2011). However, the effect of sulphur or nitrogen on AnMBR removal could be less significant at high hydrophobicity. For an example, AnMBR removal of linuron $\left(\log D_{\mathrm{pH} 7}=3.12\right)$ and clozapine $\left(\log D_{\mathrm{pH} 7}=3.23\right)$ is remarkably high and the removal of triclocarbon $\left(\log D_{\mathrm{pH}} 7\right.$ $=6.07$ ) is consistent with aerobic MBR removal (Table 2). On the other hand, the removal of the hydrophobic TrOC $\left(\log D_{\mathrm{pH} 7} \geq 3.2\right)$ triclosan from the aqueous phase by AnMBR was lower than that by aerobic MBR previously reported by Tadkaew et al. (2011), possibly because in anaerobic conditions triclosan (which does not contain either sulphur or nitrogen) is mainly removed by methanogenic archaea (Gangadharan et al., 2012). Therefore, the observed difference in TrOCs removal efficiency between anaerobic and aerobic treatment in current study could be attributed to the role of sulphur and nitrogen reducing bacteria. Indeed, it is well established that these bacteria could augment the removal of TrOCs during anaerobic treatment (Czajka and Londry, 2006; Dionisi et al., 2006; Zeng et al., 2009).

\section{[TABLE 2]}




\subsection{Fate and transport of TrOCs during the AnMBR process}

Relatively constant TrOC concentration in both the liquid and solid (sludge) phases could be observed in Figure 4. Permeate concentrations of all the hydrophobic contaminants were low. In contrast permeate concentrations of hydrophilic contaminants were highly variable (Figure 4).

This variation in permeate concentrations is attributed to the different levels of biodegradation/transformation or adsorption as discussed below.

\section{[FIGURE 4]}

Several compounds (e.g. amitriptyline, carbamazepine, triclosan, triclocarban, bisphenol A, and 4-n-nonylphenol) were detected in the inoculating sludge at considerable level even before contaminants were spiked to the AnMBR, because the seeded sludge was obtained from a domestic wastewater treatment plant. Accumulation of some TrOCs in the sludge was observed once the TrOCs had been introduced to the system (Figure 4). Immediately after introducing the TrOCs, sludge concentrations of most compounds were higher than the background levels (Figure 4). Notable accumulation of several TrOCs (e.g., atenolol, trimethoprim, diclofenac, carbamazepine, gemfibrozil, amitriptyline, diuron, clozapine, triclocarban and 4-n-nonylphenol) could be observed (Supplementary Data Figure S4). The accumulation of these TrOCs in sludge could be attributed to their resistance to biodegradation and high SRT of the AnMBR system (Abargues et al., 2012).

TrOC adsorption onto sludge can be governed by their hydrophobicity. Amitriptyline was the most abundant TrOC in sludge $(1662 \mathrm{ng} / \mathrm{g})$ since it is moderately hydrophobic $\left(\log D_{\mathrm{pH}}=2.28\right)$ and is also moderately persistent to biodegradation (Figure 4). Indeed, biodegradability is also an important factor governing the accumulation of TrOCs in the sludge phase during AnMBR treatment. Among the seven hydrophobic TrOCs, five (i.e., clozapine, triclocarban, triclosan, bisphenol A, and 4-n-nonylphenol) showed considerable accumulation in sludge (Figure 4). On the other hand, despite their hydrophobicity, the accumulation of linuron and diazinon in sludge was small (Figure 4) and was only discernible when examining their concentration in the sludge phase as a function of time (Supplementary Data Figure S4). As noted in section 3.2, both linuron and diazinon are nitrogen bearing compounds and thus they are amendable to anaerobic biodegradation. 
Despite the observed accumulation of some TrOCs in the sludge, biodegradation was still the main removal mechanism by AnMBR of all 27 TrOCs investigated in this study (Figure 5). This is because adsorption significantly increases the retention time of TrOCs in the biological reactor. In other words, there is significantly more time to biodegrade these TrOCs. As can be seen from Figure 5, in term of mass distribution, for almost all of hydrophobic TrOCs, biodegradation accounted for more than $80 \%$ while adsorption accounted for less than $20 \%$. Biodegradation also accounted for most of the removal of hydrophilic TrOCs, although the distribution varied significantly from 6 to $99 \%$. Among these hydrophilic TrOCs, only those that are recalcitrant contaminants (containing EWGs) showed discernible accumulation in the sludge phase (i.e., diuron, diazepam, carbamazepine, diclofenac, triamterene, amitriptyline and trimethoprim). However, adsorption was low and only considerable for amitriptyline (18\%).

\section{[FIGURE 5]}

Results obtained from this study (Figure 5) are broadly consistent with the qualitative framework to predict TrOCs removal by aerobic MBR previously proposed by Tadkaew et al. (2011). As can be seen in Figure 5, the removal of TrOCs by AnMBR treatment also depends mainly on their hydrophobicity and molecular properties (i.e. the presence of EWGs and EDGs in their molecular structure). Hydrophobic TrOCs containing only EDGs are readily biodegradable $(>96 \%)$. Biodegradation also plays an important role in the removal of hydrophobic TrOCs containing both EWGs and EDGs ( $>70 \%)$. Hydrophilic TrOCs containing only EDGs are also readily biodegradable $(>70 \%)$, gemfibrozil being the only exception. Low biodegradation/transformation of gemfibrozil could be due to the absence of nitrogen/sulphur as discussed in Section 3.2. Biodegradation/transformation of hydrophilic TrOCs containing EWGs in their molecular structure could vary from low to moderate $(6-70 \%)$. The presence of nitrogen could partially affect the biodegradation/transformation of recalcitrant hydrophilic TrOCs where high biodegradation could be expected of contaminants with higher number of nitrogen. For example, contaminants with at least two nitrogen atoms (e.g., carbamazepine, simazine, atrazine, diuron, and diazepam) could be highly biodegraded (25-67\%) compare to the contaminants with one or without any nitrogen atom (e.g., ketoprofen, primidone, ibuprofen and DEET) (6-14\%). Nevertheless, removal by biodegradation of hydrophilic contaminants with strong EWGs only (e.g., diclofenac) was negligible regardless the presence of nitrogen. 


\section{Conclusion}

Results reported here show a clear relationship between hydrophobicity and molecular features (i.e., functional groups and the presence of nitrogen/sulphur) of TrOCs and their fate during AnMBR treatment. Hydrophobic TrOCs were well removed by AnMBR treatment. Hydrophilic TrOCs containing electron donating functional groups were also well removed while most hydrophilic TrOCs containing electron withdrawing functional groups were poorly removed by AnMBR treatment. The removal of TrOCs by AnMBR is attributed mostly to biodegradation. Adsorption and subsequent accumulation of TrOCs in sludge were only observed for several persistent compounds that are moderately or highly hydrophobic.

\section{Acknowledgements}

The authors would like to thank the University of Wollongong for $\mathrm{PhD}$ scholarship support to Kaushalya C Wijekoon.

\section{References}

[1] Abargues, M.R., Robles, A., Bouzas, A., Seco, A. 2012. Micropollutants removal in an anaerobic membrane bioreactor and in an aerobic conventional treatment plant. Water Science \& Technology, 65, 2242-2250.

[2] Alidina, M., Hoppe-Jones, C., Yoon, M., Hamadeh, A.F., Li, D., Drewes, J.E. 2014. The occurrence of emerging trace organic chemicals in wastewater effluents in Saudi Arabia. Sci. Total Environ., 478, 152-162.

[3] Alturki, A., McDonald, J., Khan, S.J., Hai, F.I., Price, W.E., Nghiem, L.D. 2012. Performance of a novel osmotic membrane bioreactor (OMBR) system: Flux stability and removal of trace organics. Bioresour. Technol., 113, 201-206.

[4] Brack, W., et al. The SOLUTIONS project: Challenges and responses for present and future emerging pollutants in land and water resources management. Sci. Total Environ., 503504, 22-31.

[5] Carballa, M., Omil, F., Ternes, T., Lema, J.M. 2007. Fate of pharmaceutical and personal care products (PPCPs) during anaerobic digestion of sewage sludge. Water Res., 41, 2139-2150.

[6] Chang, S. 2014. Anaerobic Membrane Bioreactors (AnMBR) for Wastewater Treatment. Advances in Chemical Engineering and Science, 4, 56-61.

[7] Chang, S., Hufnagel, D. 2013. Anaerobic membrane bioreactors for wastewater treatment. in: Handbook of Wastewater Treatment:Biological Methods, Technology and Environmental Impact, (Eds.) C.J. Valdez, E.M. Maradona, Nova Science Publishers, pp. 1-34. 
[8] Clara, M., Kreuzinger, N., Strenn, B., Gans, O., Kroiss, H. 2005a. The solids retention timea suitable design parameter to evaluate the capacity of wastewater treatment plants to remove micropollutants. Water Res., 39, 97-106.

[9] Clara, M., Strenn, B., Gans, O., Martinez, E., Kreuzinger, N., Kroiss, H. 2005b. Removal of selected pharmaceuticals, fragrances and endocrine disrupting compounds in a membrane bioreactor and conventional wastewater treatment plants. Water Res., 39, 4797-4807.

[10] Czajka, C.P., Londry, K.L. 2006. Anaerobic biotransformation of estrogens. Sci. Total Environ., 367, 932-941.

[11] Dionisi, D., Bertin, L., Bornoroni, L., Capodicasa, S., Papini, M.P., Fava, F. 2006. Removal of organic xenobiotics in activated sludges under aerobic conditions and anaerobic digestion of the adsorbed species. Journal of Chemical Technology \& Biotechnology, 81, 1496-1505.

[12] Eaton, A.D., Franson, M.A.H. 2005. Standard Methods for the Examination of Water and Wastewater. 21 ed. APHA, Washington DC Newyork

[13] Gangadharan, P.V.P., Anupama, V.N., Bhasi, A., Khan, S., Bhaskaran, K. 2012. Degradation of Triclosan under Aerobic, Anoxic, and Anaerobic Conditions. Appl Biochem Biotechnol, 167, 1603-1612.

[14] Hai, F.I., Li, X., Price, W.E., Nghiem, L.D. 2011. Removal of carbamazepine and sulfamethoxazole by MBR under anoxic and aerobic conditions. Bioresour. Technol., 102, 10386-10390.

[15] Kennedy, K.J., Lu, J., Mohn, W.W. 1992. Biosorption of chlorophenols to anaerobic granular sludge. Water Res., 26, 1085-1092.

[16] Khanal, S.K. 2008. Anaerobic biotechnology for bioenergy production : principles and applications. Jhon Willey \& Sons, USA.

[17] Liao, B.-Q., Kraemer, J.T., Bagley, D.M. 2006. Anaerobic Membrane Bioreactors: Applications and Research Directions. Crit Rev Environ Sci Technol, 36, 489-530.

[18] Luo, Y., Guo, W., Ngo, H.H., Nghiem, L.D., Hai, F.I., Zhang, J., Liang, S., Wang, X.C. 2014. A review on the occurrence of micropollutants in the aquatic environment and their fate and removal during wastewater treatment. Sci. Total Environ., 473-474, 619-641.

[19] Monsalvo, V.M., McDonald, J.A., Khan, S.J., Le-Clech, P. 2014. Removal of trace organics by anaerobic membrane bioreactors. Water Res., 49, 103-112.

[20] Navaratna, D., Shu, L., Baskaran, K., Jegatheesan, V. 2012. Treatment of ametryn in wastewater by a hybrid MBR system: a lab-scale study. Water Science \& Technology, $66,1317-1324$.

[21] Nghiem, L.D., Manassa, P., Dawson, M., Fitzgerald, S.K. 2014. Oxidation reduction potential as a parameter to regulate micro-oxygen injection into anaerobic digester for reducing hydrogen sulphide concentration in biogas. Bioresour. Technol., 173, 443-447.

[22] Osorio, V., Marcé, R., Pérez, S., Ginebreda, A., Cortina, J.L., Barceló, D. 2012. Occurrence and modeling of pharmaceuticals on a sewage-impacted Mediterranean river and their dynamics under different hydrological conditions. Sci. Total Environ., 440, 3-13. 
[23] Ozgun, H., Dereli, R.K., Ersahin, M.E., Kinaci, C., Spanjers, H., van Lier, J.B. 2013. A review of anaerobic membrane bioreactors for municipal wastewater treatment: Integration options, limitations and expectations. Separation and Purification Technology, 118, 89-104.

[24] Reif, R., Suárez, S., Omil, F., Lema, J.M. 2008. Fate of pharmaceuticals and cosmetic ingredients during the operation of a MBR treating sewage. Desalination, 221, 511-517.

[25] Samaras, V.G., Stasinakis, A.S., Mamais, D., Thomaidis, N.S., Lekkas, T.D. 2013. Fate of selected pharmaceuticals and synthetic endocrine disrupting compounds during wastewater treatment and sludge anaerobic digestion. Journal of Hazardous Materials, 244-245, 259-267.

[26] Schwarzenbach, R.P., Escher, B.I., Fenner, K., Hofstetter, T.B., Johnson, C.A., von Gunten, U., Wehrli, B. 2006. The Challenge of Micropollutants in Aquatic Systems. Science, 313, 1072-1077.

[27] Shoener, B.D., Bradley, I.M., Cusick, R.D., Guest, J.S. 2014. Energy positive domestic wastewater treatment: The roles of anaerobic and phototrophic technologies. Environmental Sciences: Processes and Impacts, 16, 1204-1222.

[28] Stasinakis, A.S. 2012. Review on the fate of emerging contaminants during sludge anaerobic digestion. Bioresour. Technol., 121, 432-440.

[29] Tadkaew, N., Hai, F.I., McDonald, J.A., Khan, S.J., Nghiem, L.D. 2011. Removal of trace organics by MBR treatment: The role of molecular properties. Water Res., 45, 24392451.

[30] Tran, N.H., Li, J., Hu, J., Ong, S. 2014. Occurrence and suitability of pharmaceuticals and personal care products as molecular markers for raw wastewater contamination in surface water and groundwater. Environmental Science and Pollution Research, 21, 4727-4740.

[31] Tran, N.H., Urase, T., Ta, T.T. 2013. A preliminary study on the occurrence of pharmaceutically active compounds in hospital wastewater and surface water in Hanoi, Vietnam. CLEAN - Soil, Air, Water, 42, 267-275.

[32] Vader, J.S., van Ginkel, C.G., Sperling, F.M.G.M., de Jong, J., de Boer, W., de Graaf, J.S., van der Most, M., Stokman, P.G.W. 2000. Degradation of ethinyl estradiol by nitrifying activated sludge. Chemosphere, 41, 1239-1243.

[33] Visvanathan, C., Abeynayaka, A. 2012. Developments and future potentials of anaerobic membrane bioreactors (AnMBRs) Membrane water treatment 3, 1-23.

[34] Wijekoon, K.C., Hai, F.I., Kang, J., Price, W.E., Guo, W., Ngo, H.H., Nghiem, L.D. 2013. The fate of pharmaceuticals, steroid hormones, phytoestrogens, UV-filters and pesticides during MBR treatment. Bioresour. Technol., 144, 247-254.

[35] Zeng, Q., Li, Y., Gu, G. 2009. Nitrate-dependent degradation of $17 \alpha$-ethinylestradiol by acclimated activated sludge under anaerobic conditions. Journal of Chemical Technology \& Biotechnology, 84, 1841-1847. 


\section{List of Tables}

Table 1: Removal efficiencies of the selected contaminants during current investigation (mean \pm standard deviation of 10 measurements) and corresponding values reported in literature.

\begin{tabular}{|c|c|c|c|c|}
\hline \multirow[b]{2}{*}{ Compound } & \multirow{2}{*}{$\begin{array}{l}\text { Current study } \\
\text { Removal (\%) }\end{array}$} & \multicolumn{3}{|c|}{ Literature } \\
\hline & & Removal (\%) & Reference & $\begin{array}{c}\text { Treatment } \\
\text { process }\end{array}$ \\
\hline Linuron & $88.1 \pm 3.2$ & 10 & Monsalvo et al. (2014) & AnMBR \\
\hline Clozapine & $99.6 \pm 0.4$ & 30 & Monsalvo et al. (2014) & AnMBR \\
\hline Bisphenol A & $99.9 \pm 0.0$ & $\begin{array}{l}35 \\
35\end{array}$ & $\begin{array}{l}\text { Monsalvo et al. (2014) } \\
\text { Samaras et al. (2013) }\end{array}$ & $\begin{array}{c}\text { AnMBR } \\
\text { AD }\end{array}$ \\
\hline Diazinon & $93.0 \pm 2.4$ & $\mathrm{NA}$ & - & - \\
\hline Triclosan & $70.3 \pm 4.2$ & $\begin{array}{l}83 \\
22\end{array}$ & $\begin{array}{c}\text { Monsalvo et al. (2014) } \\
\text { Samaras et al. (2013) }\end{array}$ & $\begin{array}{l}\text { AnMBR } \\
\text { AD }\end{array}$ \\
\hline Triclocarbon & $95.6 \pm 5.7$ & 98 & Monsalvo et al. (2014) & AnMBR \\
\hline 4-n-nonylphenol & $94.2 \pm 4.1$ & $\begin{array}{c}0^{*} \\
99 \\
100 \\
0\end{array}$ & $\begin{array}{l}\text { Abargues et al. (2012) } \\
\text { Monsalvo et al. (2014) } \\
\text { Stasinakis (2012) } \\
\text { Samaras et al. (2013) }\end{array}$ & $\begin{array}{c}\text { AnMBR } \\
\text { AnMBR } \\
\text { AD } \\
\text { AD }\end{array}$ \\
\hline Atenolol & $76.5 \pm 10.5$ & 20 & Monsalvo et al. (2014) & AnMBR \\
\hline Caffeine & $90.4 \pm 3.6$ & 75 & Monsalvo et al. (2014) & AnMBR \\
\hline Sulfamethoxazole & $99.6 \pm 0.2$ & $\begin{array}{l}80 \\
99\end{array}$ & $\begin{array}{c}\text { Monsalvo et al. (2014) } \\
\text { Carballa et al. (2007) }\end{array}$ & $\begin{array}{l}\text { AnMBR } \\
\text { AD }\end{array}$ \\
\hline Ketoprofen & $27.2 \pm 21.9$ & 21 & Monsalvo et al. (2014) & AnMBR \\
\hline Trimethoprim & $97.5 \pm 0.7$ & 40 & Monsalvo et al. (2014) & AnMBR \\
\hline Paracetamol & $85.9 \pm 5.2$ & 60 & Monsalvo et al. (2014) & - \\
\hline Naproxen & $74.7 \pm 14.6$ & $\begin{array}{c}75 \\
82-96\end{array}$ & $\begin{array}{l}\text { Monsalvo et al. (2014) } \\
\text { Carballa et al. (2007) }\end{array}$ & $\begin{array}{c}\text { AnMBR } \\
\text { AD }\end{array}$ \\
\hline Primidone & $16.6 \pm 11.5$ & 5 & Monsalvo et al. (2014) & AnMBR \\
\hline Ibuprofen & $25.3 \pm 24.1$ & $\begin{array}{c}5 \\
25-82 \\
\end{array}$ & $\begin{array}{c}\text { Monsalvo et al. (2014) } \\
\text { Carballa et al. (2007) }\end{array}$ & $\begin{array}{c}\text { AnMBR } \\
\text { AD }\end{array}$ \\
\hline Triamterene & $75.3 \pm 9.9$ & NA & - & - \\
\hline Diclofenac & $2.8 \pm 1.7$ & $\begin{array}{c}5 \\
42-83 \\
\end{array}$ & $\begin{array}{c}\text { Monsalvo et al. (2014) } \\
\text { Carballa et al. (2007) }\end{array}$ & $\begin{array}{c}\text { AnMBR } \\
\text { AD }\end{array}$ \\
\hline Carbamazepine & $39.2 \pm 21.2$ & $\begin{array}{c}10 \\
0\end{array}$ & $\begin{array}{l}\text { Monsalvo et al. (2014) } \\
\text { Samaras et al. (2013) }\end{array}$ & $\begin{array}{c}\text { AnMBR } \\
\text { AD }\end{array}$ \\
\hline Gemfibrozil & $12.2 \pm 10.7$ & 15 & Monsalvo et al. (2014) & AnMBR \\
\hline Amitriptyline & $99.6 \pm 0.23$ & 40 & Monsalvo et al. (2014) & AnMBR \\
\hline Simazine & $54.1 \pm 5.3$ & NA & - & - \\
\hline Omeprazole & $99.9 \pm 0.0$ & 23 & Monsalvo et al. (2014) & AnMBR \\
\hline DEET & $19.5 \pm 24.2$ & 5 & Monsalvo et al. (2014) & AnMBR \\
\hline Atrazine & $56.9 \pm 19.6$ & 10 & Monsalvo et al. (2014) & AnMBR \\
\hline Diuron & $43.1 \pm 23.5$ & $\mathrm{NA}$ & - & - \\
\hline Diazepam & $61.6 \pm 18.2$ & $17-78$ & Samaras et al. (2013) & $\mathrm{AD}$ \\
\hline
\end{tabular}

Note: *low removal is due to the formation of 4-nonylphenol by biotransformation of alkylphenols. AD - anaerobic digestion of sewage sludge. NA - Data not available. 
Table 2: Removal efficiencies (mean \pm standard deviation of $10-16$ measurements) of nitrogen or sulphur bearing TrOCs in the current study and in Tadkaew et al. (2011).

\begin{tabular}{|c|c|c|c|c|}
\hline \multirow[b]{2}{*}{ Compound } & \multirow[b]{2}{*}{$\begin{array}{c}\log D \text { at } \mathbf{p H} \\
7\end{array}$} & \multirow[b]{2}{*}{$\begin{array}{c}\text { Number of } \mathrm{N} / \mathrm{S} \\
\text { in molecular } \\
\text { structure }\end{array}$} & \multicolumn{2}{|c|}{ Removal (\%) } \\
\hline & & & $\begin{array}{c}\text { AnMBR- } \\
\text { Current } \\
\text { study }\end{array}$ & $\begin{array}{c}\text { Aerobic MBR- } \\
\text { Tadkaew et al. } \\
\text { (2011) }\end{array}$ \\
\hline Atenolol & -2.09 & $2 \mathrm{~N}$ & $76.5 \pm 10.5$ & $96.9 \pm 0.2$ \\
\hline Caffeine & -0.63 & $4 \mathrm{~N}$ & $90.4 \pm 3.6$ & $49.6 \pm 4$ \\
\hline Sulfamethoxazole & -0.22 & $3 \mathrm{~N}$ & $99.6 \pm 0.2$ & $91.9 \pm 0.6$ \\
\hline Trimethoprim & 0.27 & $4 \mathrm{~N}$ & $97.5 \pm 0.7$ & $16.6 \pm 3.7$ \\
\hline Paracetamol & 0.47 & $1 \mathrm{~N}$ & $85.9 \pm 5.2$ & $95.1 \pm 3.4$ \\
\hline Primidone & 0.83 & $2 \mathrm{~N}$ & $16.6 \pm 11.5$ & $12.4 \pm 4.3$ \\
\hline Triamterene & 1.03 & $7 \mathrm{~N}$ & $75.3 \pm 9.9$ & $27.9 \pm 6.3$ \\
\hline Diclofenac & 1.77 & $1 \mathrm{~N}$ & $2.8 \pm 1.7$ & $17.3 \pm 4.2$ \\
\hline Carbamazepine & 1.89 & $2 \mathrm{~N}$ & $39.2 \pm 21.2$ & $13.4 \pm 4.3$ \\
\hline Amitriptyline & 2.28 & $1 \mathrm{~N}$ & $99.6 \pm 0.2$ & $97.8 \pm 0.8$ \\
\hline Omeprazole & 2.35 & $3 \mathrm{~N}$ and $1 \mathrm{~S}$ & 99.9 & $62.1 \pm 3.5$ \\
\hline DEET & 2.42 & $1 \mathrm{~N}$ & $19.5 \pm 24.2$ & $4.6 \pm 2.7$ \\
\hline Atrazine & 2.64 & $2 \mathrm{~N}$ & $56.9 \pm 19.6$ & $4.4 \pm 3.7$ \\
\hline Linuron & 3.12 & $2 \mathrm{~N}$ & $88.1 \pm 3.2$ & $21.1 \pm 4.1$ \\
\hline Clozapine & 3.23 & $4 \mathrm{~N}$ & $99.6 \pm 0.4$ & $84.8 \pm 5.4$ \\
\hline Triclocarbon & 6.07 & $2 \mathrm{~N}$ and $2 \mathrm{Cl}$ & $95.6 \pm 5.7$ & $>98$ \\
\hline Simazine & 2.28 & $5 \mathrm{~N}$ & $54.1 \pm 5.3$ & - \\
\hline Diuron & 2.68 & $2 \mathrm{~N}$ & $43.1 \pm 23.5$ & - \\
\hline Diazepam & 2.8 & $2 \mathrm{~N}$ and $1 \mathrm{Cl}$ & $61.6 \pm 18.2$ & - \\
\hline Diazinon & 3.77 & $2 \mathrm{~N}$ and $1 \mathrm{~S}$ & $93.0 \pm 2.4$ & - \\
\hline Bisphenol A & 3.64 & - & 99 & 90.4 \\
\hline Triclosan & 5.28 & - & 70 & $>91.8$ \\
\hline 4-n-nonylphenol & 6.14 & - & 94 & 99.3 \\
\hline Ketoprofen & 0.19 & - & $27 \pm 21$ & 70.5 \\
\hline Naproxen & 0.73 & - & $74 \pm 14$ & $40.1 \pm 2.8$ \\
\hline Ibuprofen & 0.94 & - & $25 \pm 24$ & $96.7 \pm 0.7$ \\
\hline Gemfibrozil & 2.07 & - & $12 \pm 11$ & $98.9 \pm 0.1$ \\
\hline
\end{tabular}




\section{List of Figure Captions}

Figure 1: (a) COD and TN removal and (b) biogas production during acclimatization and TrOC removal experiment.

Figure 2: Average aqueous phase removal of TrOCs during AnMBR treatment. Error bars represent the standard deviation of 10 measurements (duplicate samples taken once a week for five weeks). $\log D$ denotes the values at $\mathrm{pH} 7$.

Figure 3: Aqueous phase removal of TrOCs according to hydrophobicity and functional groups (A) hydrophilic contaminants with EDGs only (B) hydrophilic contaminants with EWGs, and (C) Hydrophobic contaminants. Removal efficiency represents the average value of duplicate samples taken once a week for five weeks. $\log D$ denotes the values at $\mathrm{pH} 7$.

Figure 4: Concentration of TrOCs in aqueous and sludge phases. Error bars represent the standard deviation of duplicate samples taken once a week for five weeks.

Figure 5: Removal mechanisms of TrOCs during AnMBR treatment according to hydrophobicity and functional groups; (A) hydrophilic contaminants with EDGs, (B) hydrophilic contaminants EWGs, and (C) hydrophobic contaminants. 

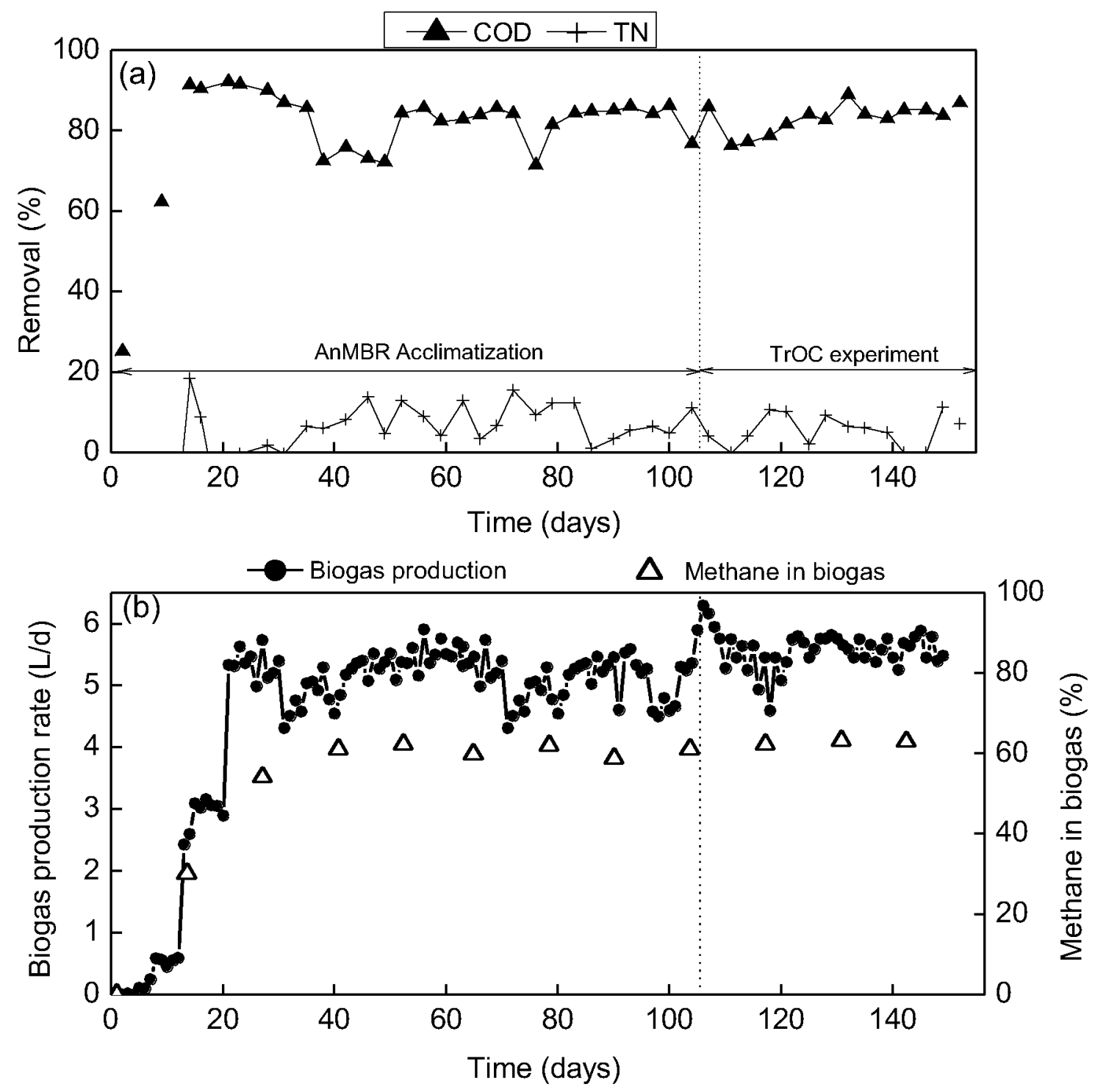

Figure 1 


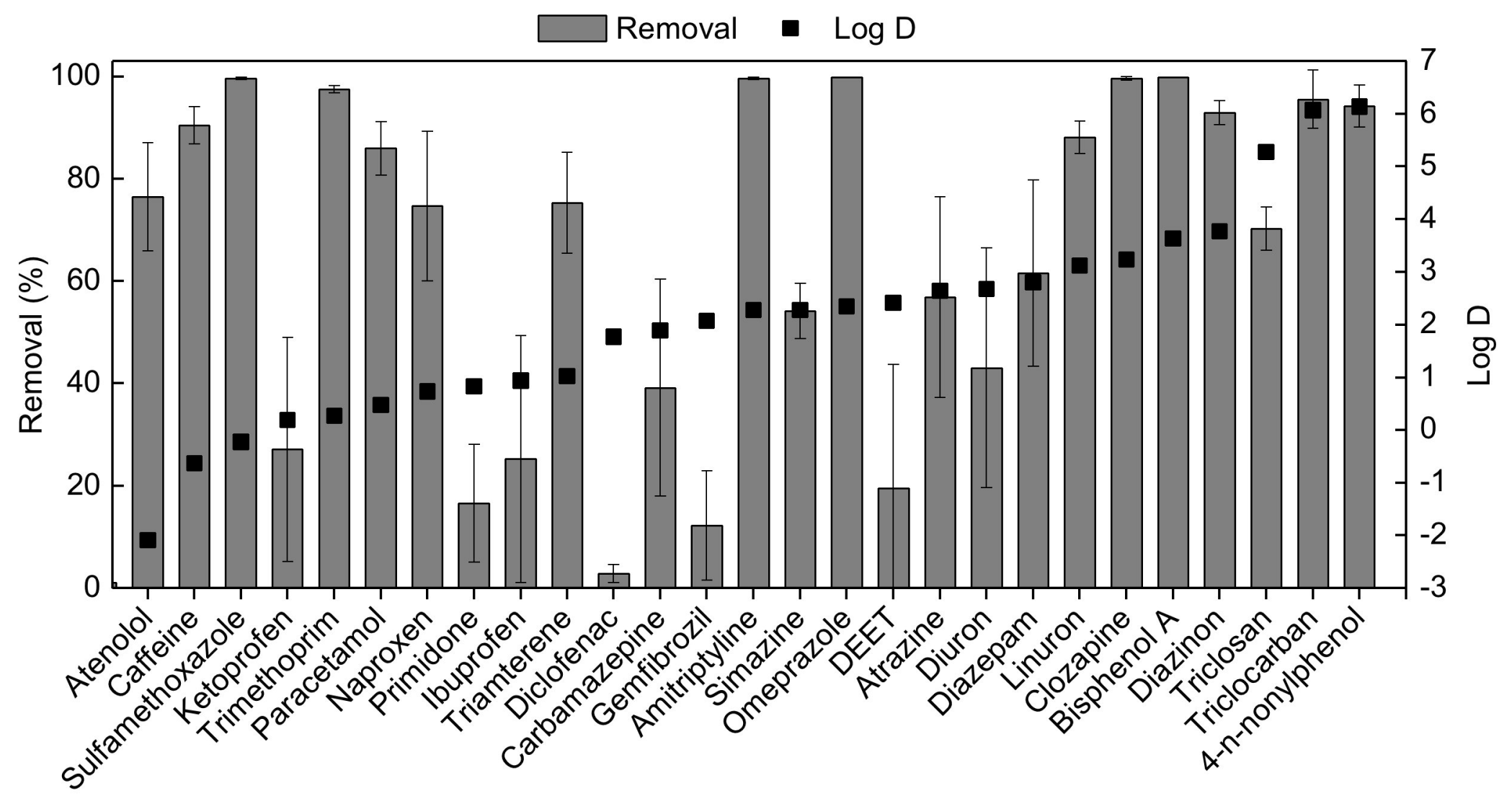

Figure 2 


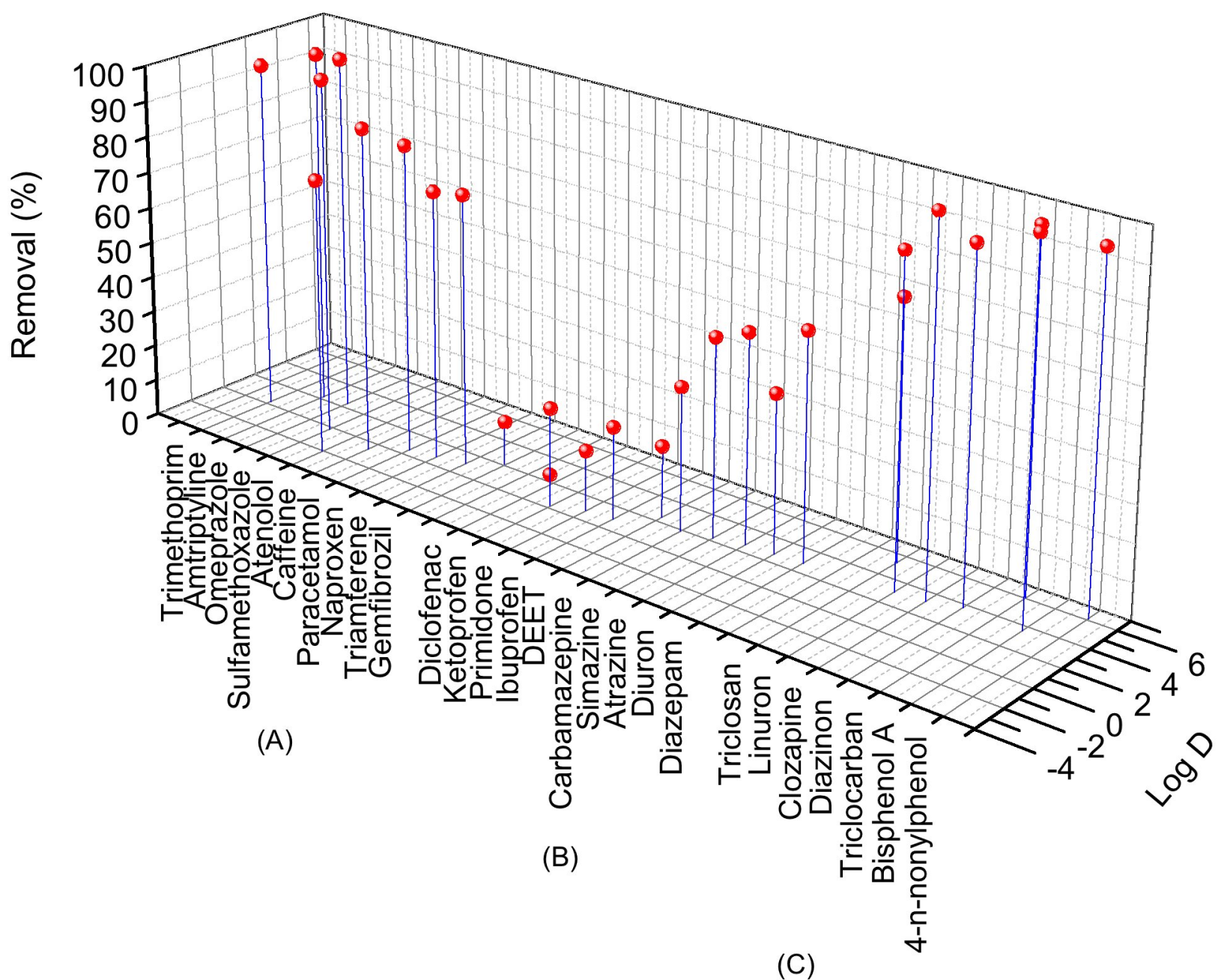

Figure 3 

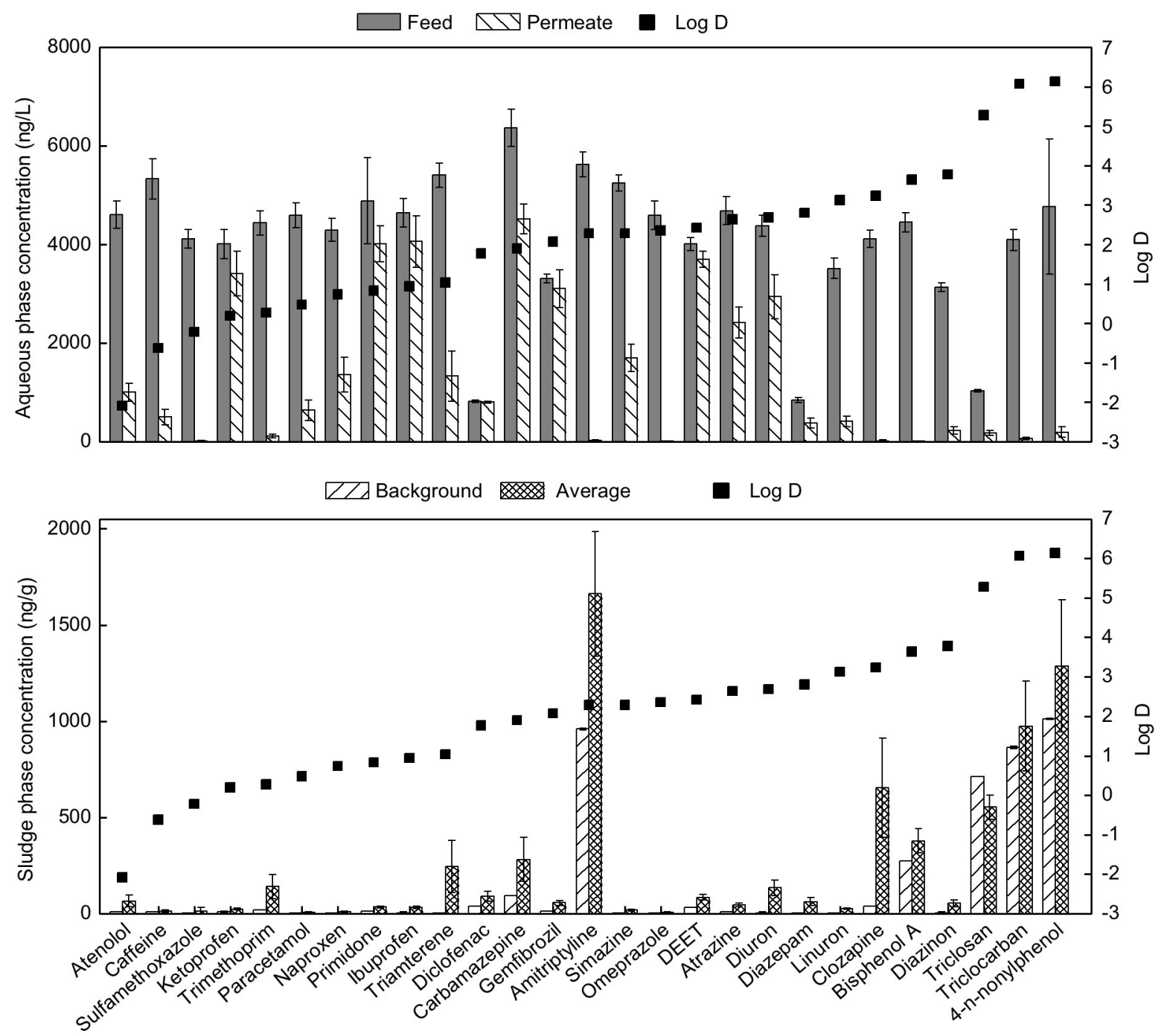

Figure 4 


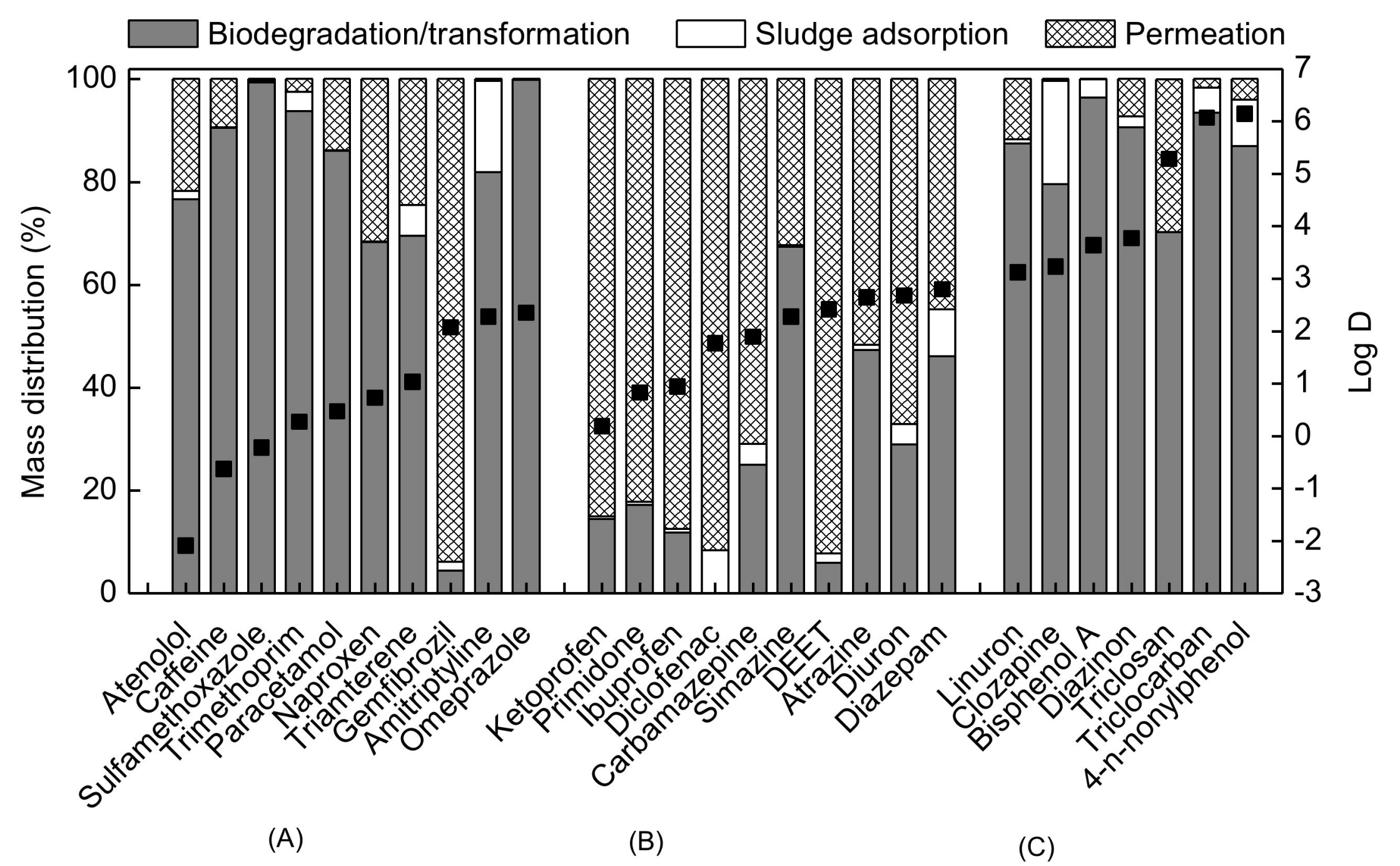

Figure 5 


\title{
Development of a predictive framework to assess the removal of trace organic chemicals by anaerobic membrane bioreactor
}

\author{
Supplementary Data
}

\section{Bioresource Technology}

February 2015

Kaushalya C. Wijekoon ${ }^{\text {a }}$, James McDonald ${ }^{\text {b }}$, Stuart J. Khan ${ }^{\text {b }}$ Faisal I. Hai ${ }^{\text {a }}$, William E. Price ${ }^{\mathrm{c}}$ and Long D. Nghiem ${ }^{\mathrm{a}}$,

${ }^{a}$ Strategic Water Infrastructure Laboratory, School of Civil Mining and Environmental Engineering, University of Wollongong, Wollongong, NSW 2522, Australia

${ }^{\mathrm{b}}$ School of Civil \& Environmental Engineering, University of New South Wales, NSW 2052, Australia

${ }^{c}$ Strategic Water Infrastructure Laboratory, School of Chemistry, University of Wollongong, Wollongong, NSW 2522, Australia

* Corresponding author: Long Duc Nghiem, Email: longn@uow.edu.au; Ph +61 242214590 


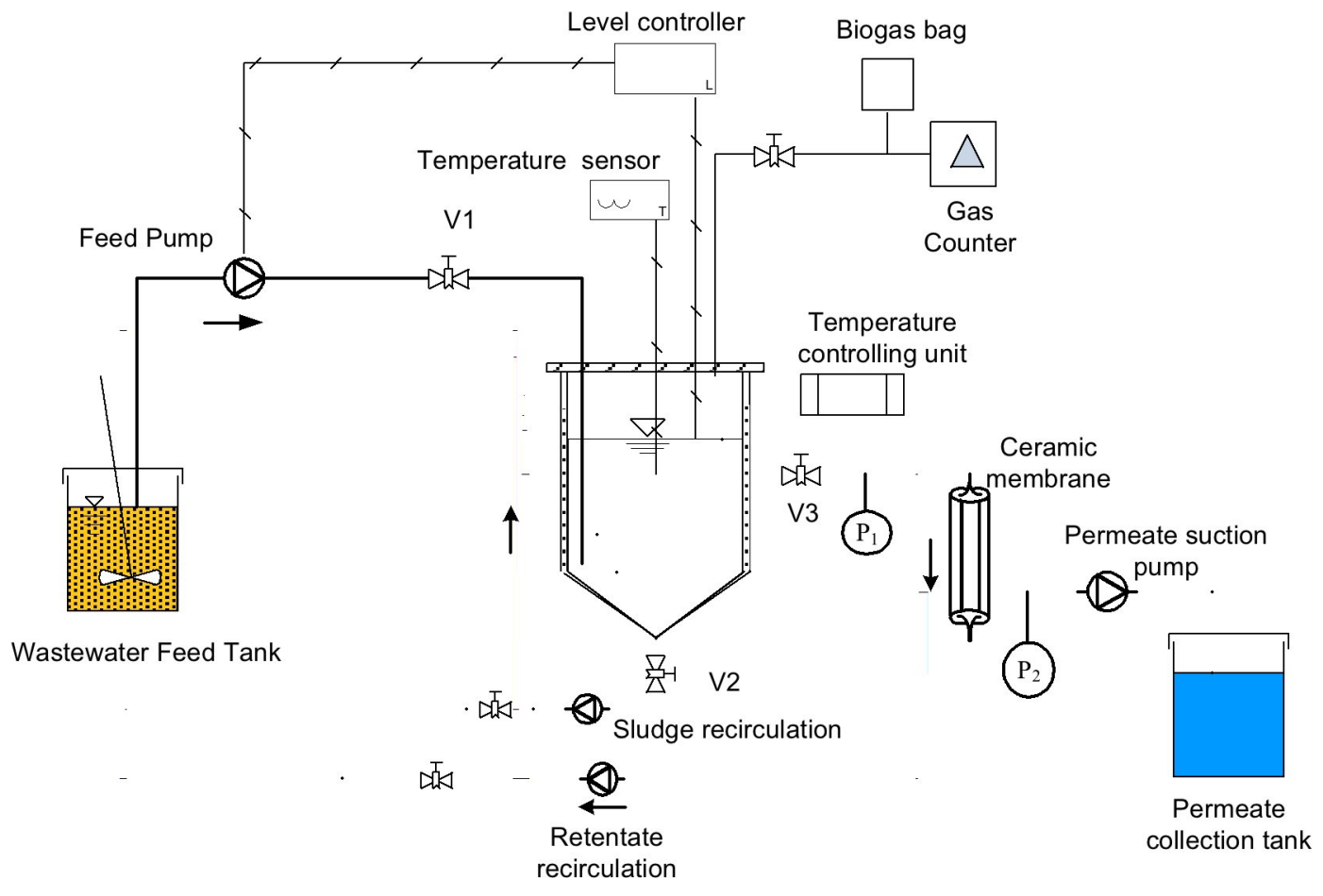

(a)

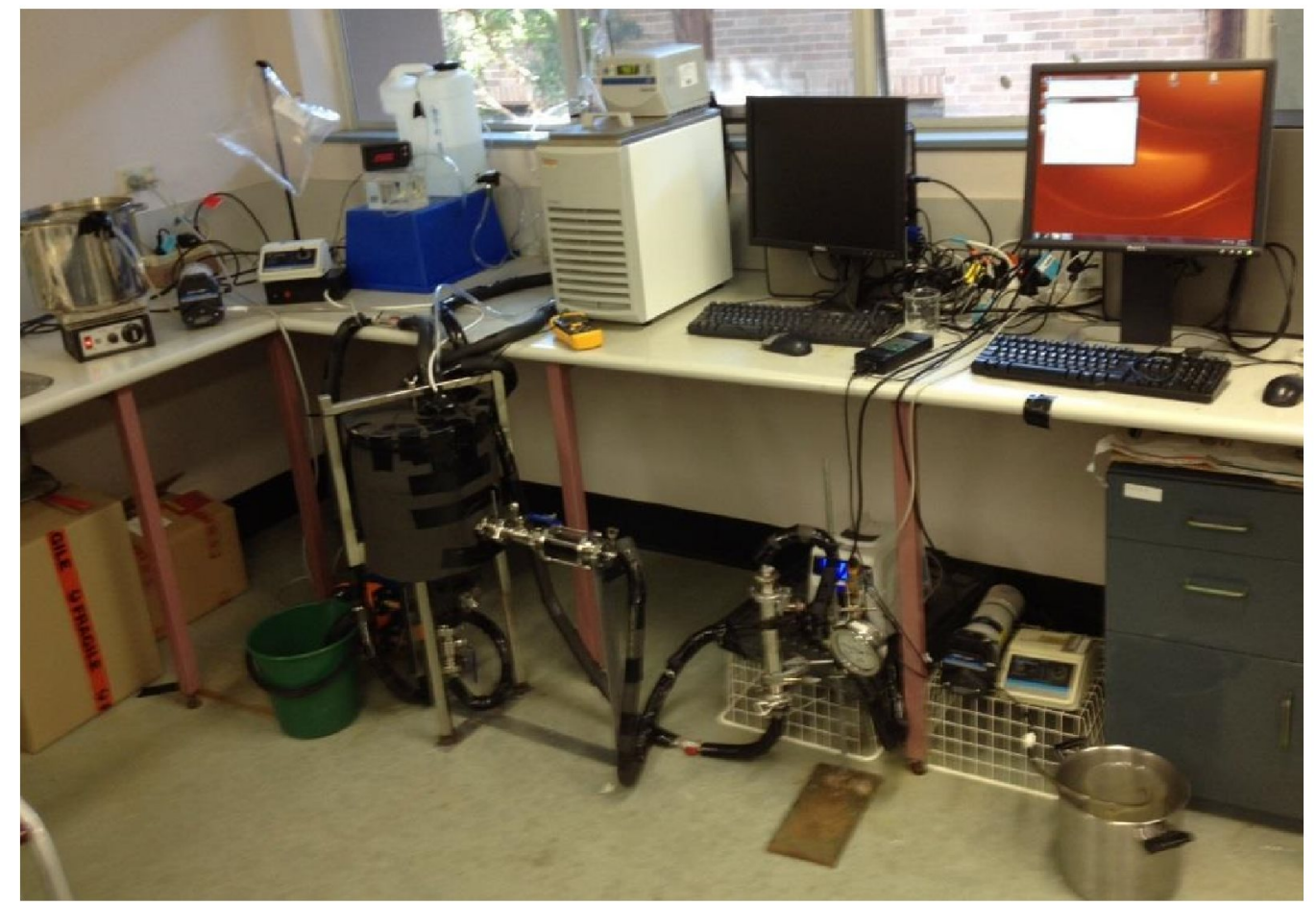

(b)

Figure S1: (a) Schematic diagram and (b) picture of the anaerobic membrane bioreactor (AnMBR) 


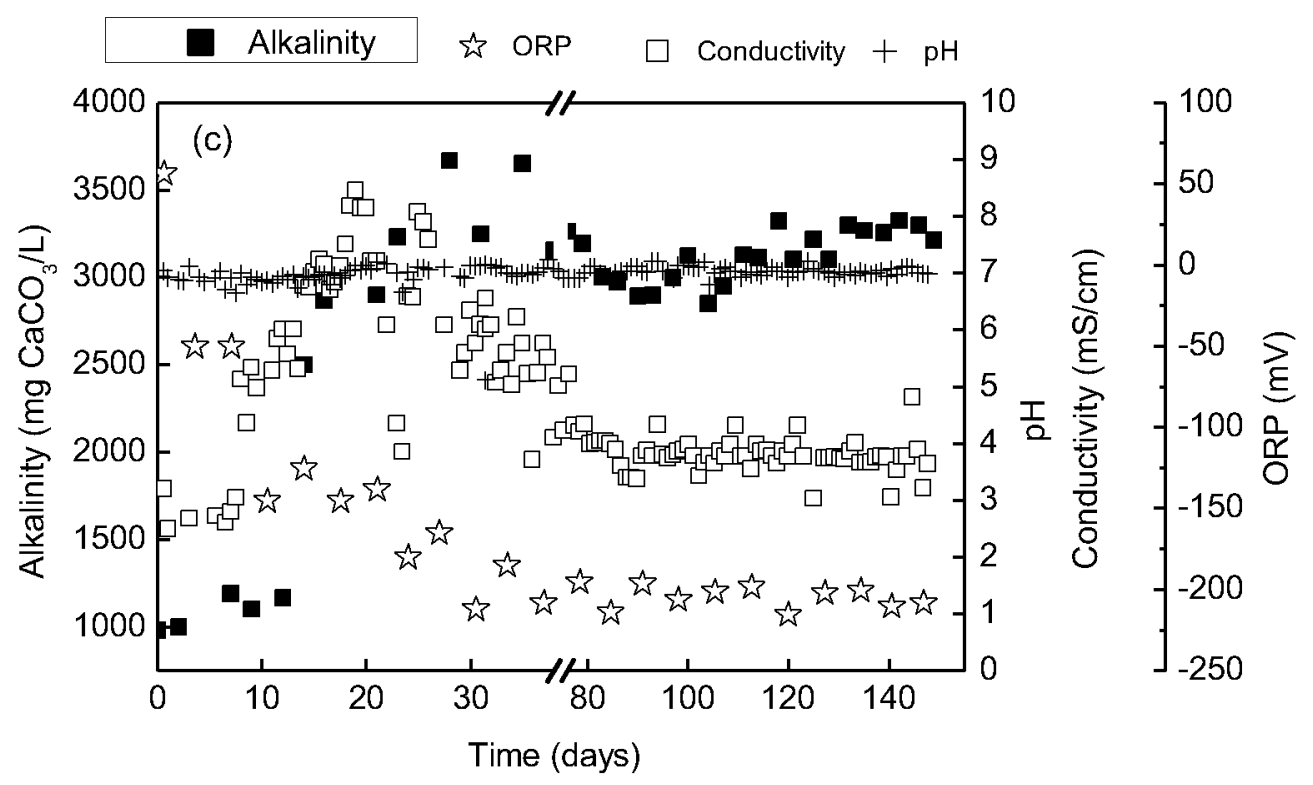

Figure S2: Alkalinity, conductivity, $\mathrm{pH}$ and $\mathrm{ORP}$ of mixed liquor during acclimatization and TrOC removal experiment.

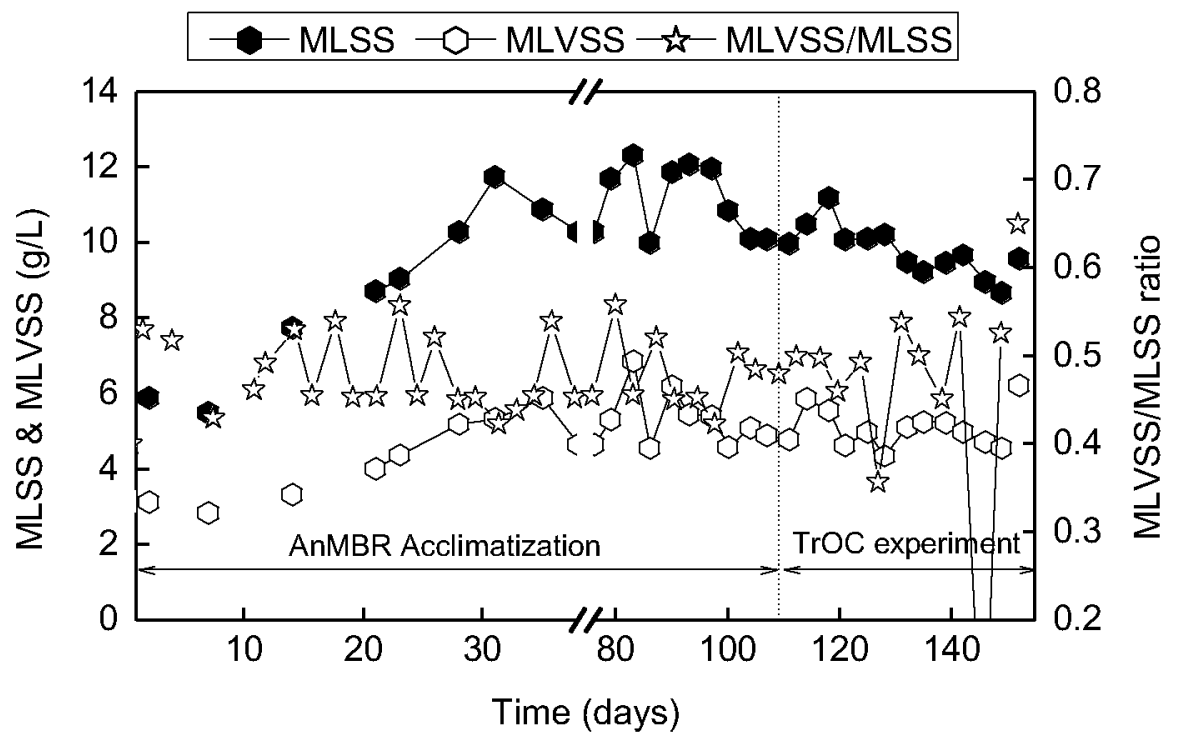

Figure S3: MLSS and MLVSS/MLSS ratio of AnMBR system during acclimatization and $\mathrm{TrOC}$ removal experiment 


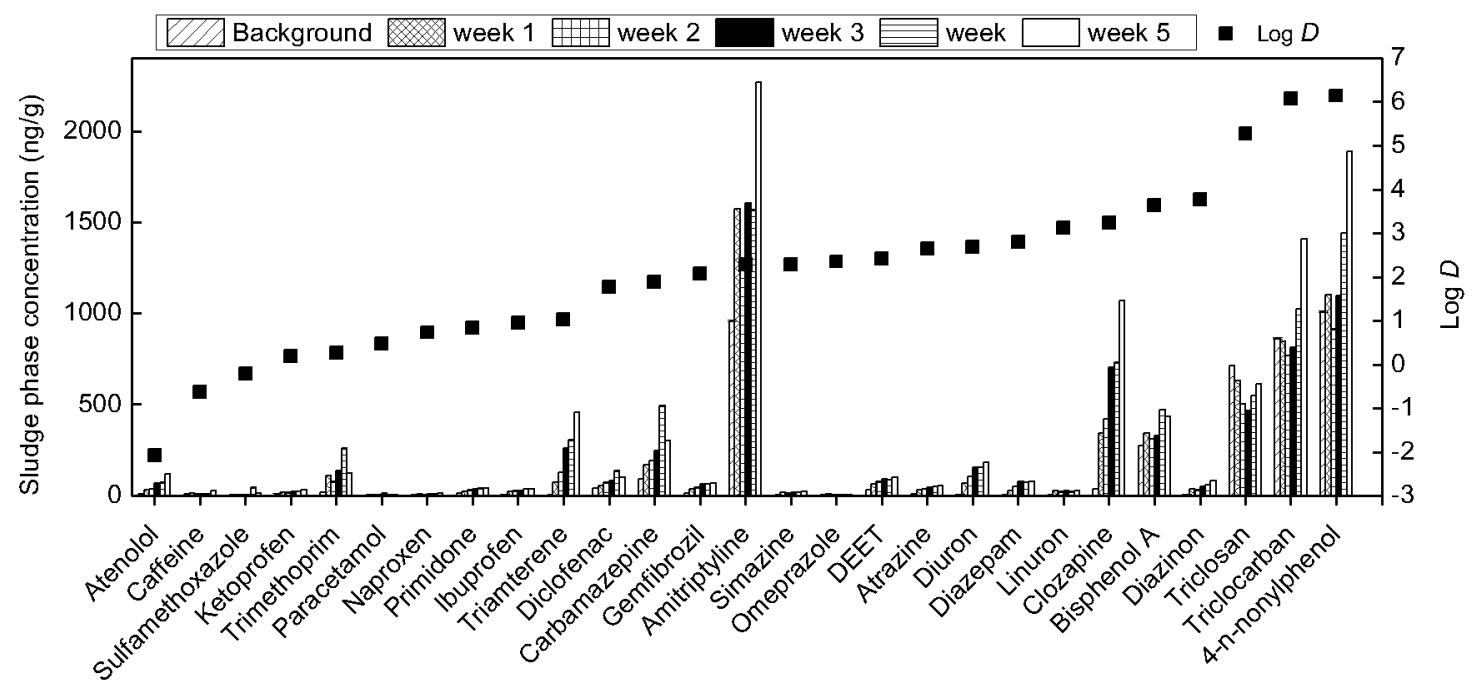

Figure S4: Variation of solid phase concentration of TrOCs with time 
Table S1: Physicochemical properties of the selected TrOCs

\begin{tabular}{|c|c|c|c|}
\hline Compound & Molecular structure & $\begin{array}{c}\text { Molecular weight } \\
\text { (g/mol) }\end{array}$ & $\begin{array}{c}\log D \text { at } \\
\text { pH } 7\end{array}$ \\
\hline Atenolol & & 266.34 & -2.09 \\
\hline Caffeine & & 194.19 & -0.63 \\
\hline Sulfamethoxazole & & 253.28 & -0.22 \\
\hline Ketoprofen & & 254.30 & 0.19 \\
\hline Trimethoprim & & 290.32 & 0.27 \\
\hline Paracetamol & & 151.16 & 0.47 \\
\hline Naproxen & & 230.30 & 0.73 \\
\hline Primidone & & 218.25 & 0.83 \\
\hline Ibuprofen & & 206.30 & 0.94 \\
\hline Triamterene & & 253.26 & 1.03 \\
\hline Diclofenac & & 296.15 & 1.77 \\
\hline
\end{tabular}




\begin{tabular}{|c|c|c|c|}
\hline Compound & Molecular structure & $\begin{array}{c}\text { Molecular weight } \\
(\mathrm{g} / \mathrm{mol})\end{array}$ & $\begin{array}{c}\log D \text { at } \\
\text { pH } 7\end{array}$ \\
\hline Carbamazepine & & 236.27 & 1.89 \\
\hline Gemfibrozil & & 250.30 & 2.07 \\
\hline Amitriptyline & & 277.40 & 2.28 \\
\hline Simazine & & 201.66 & 2.28 \\
\hline Omeprazole & & 345.42 & 2.35 \\
\hline DEET & & 191.27 & 2.42 \\
\hline Atrazine & & 215.68 & 2.64 \\
\hline Diuron & & 233.09 & 2.68 \\
\hline Diazepam & & 284.74 & 2.80 \\
\hline Linuron & & 249.09 & 3.12 \\
\hline
\end{tabular}




\begin{tabular}{|c|c|c|c|}
\hline Compound & Molecular structure & $\begin{array}{c}\text { Molecular weight } \\
\text { (g/mol) }\end{array}$ & $\begin{array}{c}\log D \text { at } \\
\text { pH } 7\end{array}$ \\
\hline Clozapine & & 326.82 & 3.23 \\
\hline Bisphenol A & & 228.29 & 3.64 \\
\hline Diazinon & & 304.35 & 3.77 \\
\hline Triclosan & & 289.54 & 5.28 \\
\hline Triclocarban & & 315.58 & 6.07 \\
\hline Nonylphenol & & 220.35 & 6.14 \\
\hline
\end{tabular}

Note: Molecular formulae, molecular weight, $\log D$, vapour pressure and water solubility values were from SciFinder Scholar. 